\title{
11. Volunteers as Agents of Co-production: The example of NSW State Reserves
}

\author{
Peter Houghton
}

I have worked in the field of land and natural resource management for over 40 years and currently look after the State Reserves in New South Wales. I am currently co-producing service outcomes with local communities through the preparation of plans for the management of these public recreation reserves. My background is as a practitioner; and I have a wealth of experience working collaboratively with other public officers and co-producing services with members of the public. In my contribution to this volume I will outline the role of Crown lands in NSW and given examples of effective mobilisation of volunteers and how the general public can co-produce the delivery of service outcomes.

In New South Wales, Crown lands are all the land that is owned by the state government. It is administered under the Crown Lands Act and is managed by the Crown Lands Division, a part of the Department of Primary Industries (DPI).

In its 2010 annual report, the division outlined its aim as managing Crown lands to deliver better outcomes for the people of New South Wales - including the use of such land for public enjoyment. This last part of the aim - the focus on public enjoyment - is what I found most interesting, because this obviously greatly assists the ability to co-produce service outcomes and mobilise volunteers.

The division manages approximately 43.7 million hectares of land - almost half of the state. This land comprises 35,000 reserves; 17 state parks; 270 caravan parks and camping grounds; 6500 travelling stock reserves; eight major recreational tracks and trails; seven national surfing reserves; most beaches, estuaries and waterways; showgrounds; country and community halls; heritage assets including lighthouses; convict-built ports; public buildings; and historical mine sites. It is a broad portfolio, and obviously a significant interface with the public of New South Wales.

A number of the 35,000 reserves are managed under trust. And, of particular relevance to the topic of this chapter, are those which have a community trust 
board, managed by reserve trust managers. There are approximately 700 such boards statewide, and they are given responsibility for the care, control and management of their reserve.

Further, the network of state parks are what I believe to be an example of successful co-production. These parks are scattered throughout the state, on the coast and inland, but particularly by major water resources inland. They offer a range of facilities for public enjoyment including accommodation (caravan and camping facilities, cabins and so on). Seven of those are currently managed by volunteer community trust boards. These are the state parks of Belmont Wetlands, Newcastle, Lake Keepit, Wyangala, Grabine, Copeton and Burrinjuck (on one of the major water supplies in inland New South Wales) and Killalea (on the state's South Coast).

Each of these trust boards, like all the other trust boards that are associated with the DPI, enjoy a level of autonomy that includes allowing them to enter into leases and licenses, setting entry fees and accommodation rates, employing people to work for them and determining the development of the land. So, although they do not conduct their business for private profit, they aim to maintain a level of income to operate their day-to-day activities. Importantly, they are not a branch of a government department but the government works in partnership with them to benefit the community.

To be a member of a trust board is an honorary, volunteer position. Each board has at least three and up to seven members, and they are responsible directly to the minister administering the Crown Lands Act. The tenure of board members is determined by their capacity to stay in their position. A member of the board of the Burrinjuck Waters State Park has served for over 50 years; another, on the board of the Copeton State Park, has served for over 40 years. Obviously these two volunteers are enjoying their stint in co-producing outcomes. And yet, volunteers are not entitled to any financial benefits; they can recoup out-ofpocket expenses incurred for carrying out their duties, but they are not entitled to any payment for loss of time incurred while performing board duties.

Most volunteers want to be positive and make good things happen and the volunteers who have served on the boards for a long time are truly the heart and soul of those assets. Without them, the parks would not exist because the government simply could not physically manage all of them. And yet, because of that small percentage of people who want to do the wrong thing, there has to be some monitoring from the outside. To this end there are 20 regional officers around the state, each with the responsibility of looking after the trusts.

The volunteer-run system arose primarily because of the lack of public knowledge about access to the state parks. There was a desire to improve facilities 
within these parks and, in fact, a key barrier to that was a lack of coordination between government and the individual trusts. A breakthrough came with the establishment of the State Parks Trust Advisory Board.

To improve coordination, a dialogue was developed to provide an internal support network to enable strategic planning for improved park management.

The accountability and reporting regimes of the advisory board are selfregulated, and this has resulted in improved coordination and implementation of policies such as a comprehensive marketing strategy, where there is now a unified brand. An annual reporting system allows the DPI to monitor the improvements or otherwise in each park.

The adjustments that have been made include a greater focus on the issues affecting state parks so that we could address the concerns of the trusts. The successful marketing strategy has increased visitation over the last few years by at least five per cent in each year. Therefore, there is improved delivery of product ensuring the consistency, equity and accountability of those services.

In respect to central government agencies, they were neither an enabler nor a drag on these initiatives. Going into the future, however, I believe it is important for the State Parks Trust Advisory Board to establish linkages with both central and other agencies for the provision or the co-production of resources.

Both the department and the advisory board must obviously work in conjunction with private landholders throughout New South Wales whose properties border Crown land. In fact, we often have a close working relationship with the neighbours, particularly in rural areas of the state, where there is extensive need for weed control and feral animal control. In a few cases we have even developed our fire management plans only after consulting the neighbour's plans first, so as to make sure of having a coordinated effort across the board. As our trust boards comprise of volunteers, it also helps that they are often neighbours in their private lives to the same people who border Crown Lands.

The second example I would like to mention is the caravan and camping grounds. These are an excellent case of the public successfully participating in policy development and co-producing outcomes. This has been facilitated by the introduction of the Caravan and Camping New South Wales website. Again, as with the state parks, the opportunity to develop the website arose as a result of recognition by the public, as well as by departmental officers, of the need to improve those facilities. The key barrier to achieving that was a lack of a comprehensive database to inventory the condition of facilities at caravan and camping grounds on Crown Lands across the state. To rectify this, the caravan park operators and the division formed a partnership in order to survey the 
responses of caravan park users to the idea of such a database. These two groups also presented their plans for the database at camping shows. After this, the database was developed.

After permission was granted by each park operator to advertise their facility online, the website was then launched at a caravan and camping show in Sydney. We then established a newsletter with in excess of 20,000 subscribers, which serves as a mechanism for self-fulfilling accountability and reporting. Users have been encouraged to give us feedback, and that which we have received so far has prompted us to make a number of improvements. The feedback also provides the government with a way of monitoring compliance with government regulation so both the government and public benefit from better facilities.

The website certainly provided a focus for that. With the onset of social media, there will also be future opportunities to explore new linkages with existing and future legislation through this medium.

So, to conclude, I have two key messages. The first is to never promise something you can't deliver. Nothing dissuades potential volunteers from joining up like unrealistic commitments. Secondly, for volunteers to be effective, the organisation with which they work needs to be able to provide an internal functional support network to facilitate the ongoing activities of those volunteers. Without that support network the project will undoubtedly fail. 